\title{
Injection studies of the splenic vasculature in portal hypertension
}

\author{
FEDERICO MANENTI ${ }^{1}$ AND ROGER WILLIAMS
}

From the Department of Medicine, Royal Free Hospital, London

EDITORIAL SYNOPSIS Increased blood flow through muscle and skin is known to occur in hepatic cirrhosis. Splenic artery and vein injection studies have shown that the increased size of the spleen found in portal hypertension is accompanied by vascular changes suggesting increased blood flow. These changes consist of an increase in the number of venous and arterial channels as compared with the normal. The increase in arterial vessels was greater than venous and the changes were particularly marked in the smaller arteries. Arteriovenous anastomoses were not found, but aneurysms of the splenic artery or its main branches were found in $50 \%$ of cases. The relation of these changes to the development of portal hypertension and to vascular changes in other organs is discussed.

Most workers believe that the histological changes observed in the spleen in cirrhosis, notably dilatation of sinuses, increased reticulum, periarterial haemorrhages, and fibrosis, are the simple consequences of prolonged venous congestion. It has been repeatedly observed, however, that the size of the spleen bears little relation to the height of the portal pressure and others have suggested that the spleen plays a more active role in the production of portal hypertension in cirrhosis (Ravenna, 1940; Patrassi, Dalpalu, and Ruol, 1961; Shaldon, 1962). Arterial inflow is increased and this, together with an increased inflow through the mesenteric vessels, may also account for the rare cases of portal hypertension described in which no obstruction can be demonstrated in the portal vein or liver (Tisdale, Klatskin, and Glenn, 1959). Evidence in favour of this view is the demonstration of splenic arteriovenous shunts in cirrhosis. These were first shown histologically by Franceschini (1948) and were also thought to be present by Womack and Peters (1961), who, after injecting glass spheres of diameter 20 40 times greater than the smallest capillaries into the splenic artery at necropsy, were able to recover some from the splenic vein.

In this paper we describe techniques for the injection and preparation of latex casts and radiographic-histological preparations of the spleen in which the smallest arterial vessels are filled. Methods are described for the quantitation of the arterial and venous vasculature and the findings in patients with

${ }^{1}$ British Council fellow. cirrhosis are compared with those in a control group.

\section{MATERIAL}

Thirty-five spleens were examined, of which 34 were obtained at necropsy and one was removed surgically. They were divided into two groups. The first consisted of 12 spleens from patients with cirrhosis in all of whom the diagnosis had been confirmed by histological examination. With one exception (no. 18) all had evidence of portal hypertension during life as shown by the presence of oesophageal varices on barium swallow examination. In one (no. 22) this had also been confirmed by measurement, the intrasplenic pressure being $26 \mathrm{~mm} . \mathrm{Hg}$. Case 18 was seen for the first time shortly before death and, although the barium swallow was negative, it is likely that portal hypertension was present since prominent lower oesophageal veins and an intra-abdominal collateral circulation were present at necropsy. The second group consisted of 23 controls in whom the necropsy diagnosis varied, the commonest causes of death being coronary thrombosis and carcinoma. The age in the two groups was similar, the mean being 53.6 years (range 28-74) in the cirrhotic patients and $63 \cdot 4$ (range 33-84) in the controls.

\section{INJECTION TECHNIQUES}

Two different methods were used:

LATEX PREPARATIONS (25 SPLEENS) The material injected 
was Butakon (Butadiene copolymer Latex ML 505, supplied by Imperial Chemical Industries Limited). This consists of a stable, aqueous dispersion of very small particles of a copolymer of Butadiene and methyl methacrylate which sets after dehydration into a solid form of rubbery consistency. Preliminary studies showed that it was more suitable than the commonly used vinyl acetate because it was 'soluble' in water rather than in acetone, and this allowed a slower injection at a more controlled and steady pressure. The Butakon, which is white, was coloured with a red or blue dye also supplied by I.C.I. Ltd., according to whether the artery or vein was being injected.

The splenic artery and vein at the hilum or their main branches were cannulated and the small collaterals to the capsule and mesentery ligated. The organ was then washed. This was done through the artery with tap water at a constant pressure of about $55 \mathrm{~mm} . \mathrm{Hg}$, the organ being suspended in water to obtain a more even distribution of the washing fluid. The washing was continued until the water coming from the veins was almost clear. The time required was generally three to four hours, but varied considerably and was usually shorter in the cirrhosis group. Some tissues swelled towards the end but swelling was almost reversible if the spleen was left wrapped in absorbent cotton wool for a few hours. The artery was then injected with Butakon using a pressure of 45 to $55 \mathrm{~mm} . \mathrm{Hg}$. The pressure was maintained for three to five minutes, after which the artery was ligated. The vein was then injected for five minutes using a pressure of 5 to $15 \mathrm{~mm}$.Hg. After the injection was completed the spleens were dehydrated in methylated spirit for 10 to 15 days according to their size. The organic material was then digested. Initially this was done with concentrated hydrochloric acid but later a $10 \%$ solution of potassium hydrate at $40^{\circ} \mathrm{C}$. was used since this preserved the colour better. Finally the cast was washed gently in running tap water. The cast was of rubbery consistency and was always examined and stored under water in order to prevent collapse.

BARIUM-Gelatin PREPARATIONS (10 SPLEENS) The injection material was pre-prepared by mixing a $100 \%$ suspension of Micropaque with a $10 \%$ solution of gelatin in a proportion of $2: 1$. This was injected into the artery without previous washing. Both the container of the material and the spleen were kept during the injection in a warm bath at $37^{\circ} \mathrm{C}$. The pressure and the time of injection were similar to those described for latex preparations. After injection the specimen was stored for five to 10 minutes at $4{ }^{\circ} \mathrm{C}$. to allow the gelatin to set. Radiographs were then taken, and the spleen fixed in $10 \%$ formalin for histological examination.

\section{QUANTITATION OF VASCULARITY}

The changes in vascularity were quantitated in three ways. First in the latex preparations the spleen was weighed immediately before and at the completion of the arterial and venous injections. The difference, when expressed as a percentage of the initial weight, indicated the total capacity of the arterial and venous systems.
In a number of the latex preparations the spleen was also weighed at the completion of the arterial injection so as to determine the contribution of the arterial system to the total volume. In the barium-gelatin preparations where the artery only was injected the spleen was also weighed before and after injection so as to estimate the arterial volume.

The relative sizes of the arterial and venous systems were also determined in peripheral segments of the latex preparations. An arterial branch of 2 to $3 \mathrm{~mm}$. diameter was separated from the cast together with its accompanying vein. This was possible because of the strictly zonal type of circulation in the spleen. After complete drying the arterial and venous systems were separated and weighed. The ratio between the weights provided an estimate of their relative volumes. Spleens were examined in this way only when examination of the cast under the dissecting microscope showed even filling of both systems.

The number of arterial vessels was also quantitated. A vessel of approximately $1 \mathrm{~mm}$. diameter was separated from the latex cast, cleared from all venous vessels, spread whilst still damp on a glass slide and examined under a dissecting microscope. This procedure permitted the preservation of the finest vessels and gave them at the same time a stable support which made their handling easier. The branching vessels seen under the dissecting microscope were classified according to size, and the number of arterial branches derived from each vessel was counted, proceeding from the largest to the smallest. The smallest vessels counted were of 0.15 to $0.10 \mathrm{~mm}$. diameter, these usually ending in a brush-like bunch of straight minute vessels. The latter were not counted since they were not uniformly preserved. The number of vessels formed by each branching is an index of arterial vascularity. Counting was continued until a total of 150 to 200 of the smaller branches of each specimen was reached, and although the counts were done knowing the group to which the spleens belonged, precautions to avoid bias were taken by repeating the examination a few days later without knowledge of the previous results. Also two parts of the spleen were always examined and the final figures shown are the mean of at least four readings. The difference between the individual counts and the mean was less than $20 \%$.

\section{RESULTS}

The spleens were larger in the cirrhosis group, the mean weight of $371.6 \mathrm{~g}$. (range $153-910 \mathrm{~g}$.) being more than twice that of the control group. In the latter the mean was $163 \cdot 8 \mathrm{~g}$. and the range 79-222 $\mathrm{g}$.

SPLENIC ARTERY ANEURYSMS Inspection of the splenic artery before injection revealed small aneurysms close to the hilum in three of the cirrhosis group (nos. 17, 22, and 34). Examination of the final latex casts and of the $x$-ray films after the barium-gelatin injections showed aneurysms in another three, making a total of six $(50 \%)$ in the 


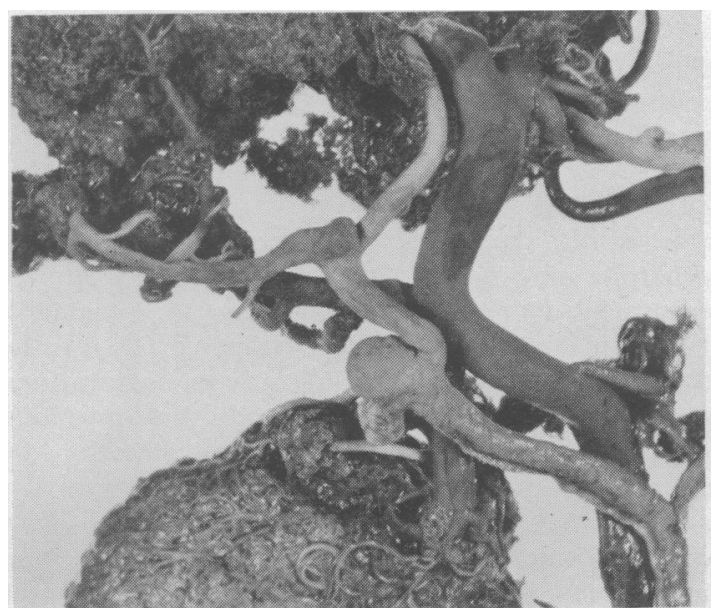

FIG. 1. Dissection of the hilum of a latex cast before digestion showing small aneurysms at the secondary and tertiary bifurcations of the splenic artery. The darker vessel shown is the splenic vein.

cirrhosis group (Fig. 1). The aneurysms were multiple in three cases and occurred predominantly at the bifurcation of vessels (Table I). In two spleens (nos. 13 and 22) they were associated with marked tortuosity of the main arterial trunk. In none of the 23 controls were aneurysms detected.

TABLE I

THE NUMBER, DIAMETER, AND LOCATION OF THE SPLENIC ARTERY ANEURYSMS

\begin{tabular}{|c|c|c|c|c|}
\hline \multirow{2}{*}{$\begin{array}{l}\text { Case } \\
\text { No. }\end{array}$} & \multirow{2}{*}{$\begin{array}{l}\text { Spleen } \\
\text { Weight } \\
\text { (g.) }\end{array}$} & \multicolumn{3}{|c|}{ Aneurysm } \\
\hline & & Number & $\begin{array}{l}\text { Diameter } \\
(\mathrm{mm} .)\end{array}$ & Situation \\
\hline \multirow[t]{3}{*}{3} & 444 & 1 & 4 & Secondary bifurcation \\
\hline & & 1 & 3 & Third bifurcation \\
\hline & & 1 & 1 & $\begin{array}{l}\text { Bifurcation of small } \\
\text { peripheral artery }\end{array}$ \\
\hline 13 & 294 & 1 & 2 & Secondary bifurcation \\
\hline 16 & 271 & 1 & 3 & Primary bifurcation \\
\hline 17 & 410 & 1 & 7 & Main trunk \\
\hline \multirow[t]{3}{*}{22} & 319 & 1 & 10 & Main trunk \\
\hline & & 2 & $2 \& 5$ & Secondary bifurcation \\
\hline & & 1 & 3 & Third bifurcation \\
\hline \multirow[t]{3}{*}{34} & 910 & 3 & $6-7$ & Primary bifurcation \\
\hline & & 9 & $2-5$ & Secondary bifurcation \\
\hline & & 15 & $1-5$ & Third and fourth bi- \\
\hline
\end{tabular}

SIZE OF ARTERIAL AND VENOUS SYSTEMS When the increase in weight of the latex preparations after injection of both artery and vein was expressed as a percentage of the initial weight the values were similar in the cirrhosis and control groups, the mean values being $14.6 \%$ and $15 \cdot 8 \%$ respectively (Fig. 2). Although the total arterial and venous volume was

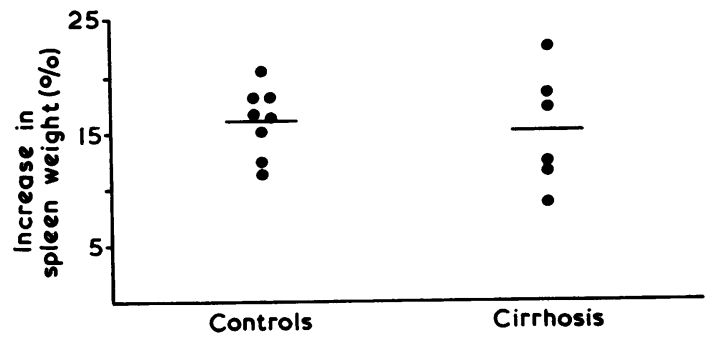

FIG. 2. The increase in spleen weight after injection of both artery and vein in the latex preparations expressed as a percentage of the initial weight.

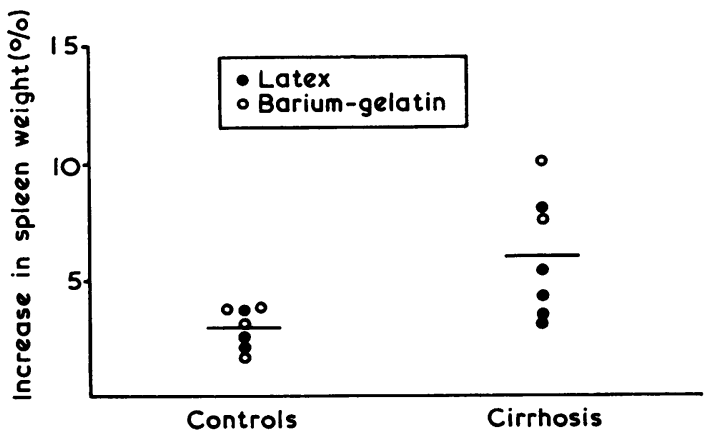

FIG. 3. The increase in spleen weight after injection of the artery alone, expressed as a percentage of the initial weight.

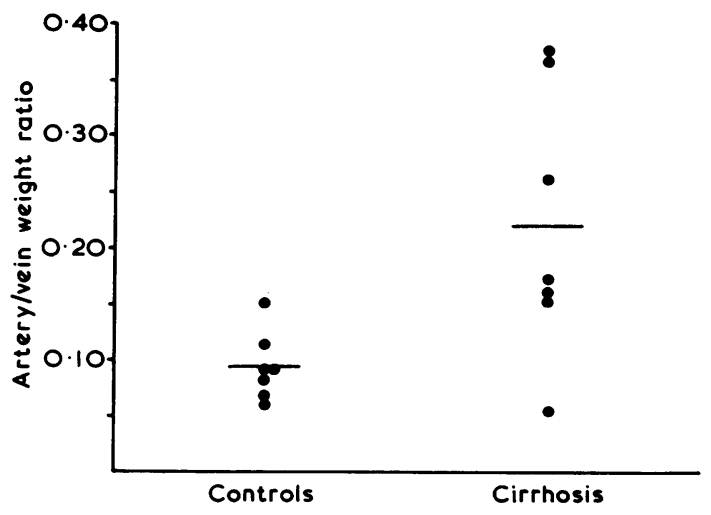

FIG. 4. Ratio of the weights of the arterial and corresponding venous system separated from peripheral segments of the latex casts.

therefore increased in cirrhosis in proportion to the greater size of the spleen the contribution of the arterial system to this volume was considerably greater. This was shown by the results in certain of the latex preparations where weights were also 
obtained after injection of the artery and in the barium-gelatin preparations in which the artery only was injected (Fig. 3). The mean increase in weight in the cirrhosis group, again expressed as a percentage of the initial weight, was $5.8 \%$ as compared with $2.9 \%$ in the controls. The results of the separate weighings of isolated arterial and venous systems from segments of the spleen also indicated an increased arterial component. The individual weights varied considerably but the mean artery to vein weight ratio was $\mathbf{0 . 2 1 8}$ in cirrhosis as compared with 0.092 in the controls (Fig. 4). One spleen in the cirrhosis group (no. 18) had a normal ratio. Excluding this spleen, the difference between the means was statistically highly significant $(p<0.01)$ but even with its inclusion the difference was significant at less than the $5 \%$ level.

NUMBER OF ARTERIAL BRANCHES Inspection of the surface of the latex casts showed a striking difference between the control and cirrhosis groups. In the latter the main colour was the red of the arterial system whilst in the controls only the blue colour of the venous system was seen, this completely surrounding the fine endings of the arteries. This difference was due to an increased number of peripheral arterial branches as was shown quantitatively by the counting technique. The ratio between the number of arterial branches of any size and the number of the preceding larger vessels from which they were derived was similar in the two groups except for the smallest branches of $100 \mathrm{~m} \mu$ diameter where the ratio was considerably higher in the cirrhosis group (Table II). The only exception was case 18 which in all respects behaved similarly to the controls. Including this spleen, the mean terminal branching ratio was $13 \cdot 2$

TABLE II

\begin{tabular}{|c|c|c|c|c|}
\hline \multirow{3}{*}{ Group } & \multicolumn{4}{|c|}{ QUANTITATION OF ARTERIAL BRANCHING ${ }^{1}$} \\
\hline & Case & Bran & atio & \\
\hline & & $B / A$ & $C / B$ & $D / C$ \\
\hline Cirrhosis & $\begin{array}{l}3 \\
12 \\
16 \\
18 \\
22 \\
35 \\
\text { Mean }\end{array}$ & $\begin{array}{l}2 \cdot 5 \\
3 \cdot 5 \\
4 \cdot 5 \\
8 \cdot 5 \\
9 \cdot 5 \\
4 \cdot 0 \\
5 \cdot 4\end{array}$ & $\begin{array}{r}12.0 \\
4 \cdot 1 \\
6.0 \\
5 \cdot 8 \\
6.0 \\
4 \cdot 5 \\
6.3\end{array}$ & $\begin{array}{r}21 \cdot 1 \\
12 \cdot 0 \\
14 \cdot 3 \\
8 \cdot 4 \\
12.9 \\
11 \cdot 0 \\
13.2\end{array}$ \\
\hline Controls & $\begin{array}{l}1 \\
10 \\
19 \\
20 \\
21 \\
23 \\
\text { Mean }\end{array}$ & $\begin{array}{l}5 \cdot 5 \\
3 \cdot 3 \\
6 \cdot 0 \\
4 \cdot 5 \\
6 \cdot 5 \\
4 \cdot 5 \\
5 \cdot 1\end{array}$ & $\begin{array}{l}6.6 \\
6 \cdot 1 \\
4 \cdot 1 \\
6.6 \\
6.6 \\
4.5 \\
5.4\end{array}$ & $\begin{array}{l}9.5 \\
9.9 \\
9.3 \\
6.4 \\
6.7 \\
8.1 \\
8.3\end{array}$ \\
\hline
\end{tabular}

${ }^{1}$ The results are expressed as a branching ratio, this being the average number of vessels of a certain size derived from a vessel of preceding larger size. Arterial sizes: $A=0.8-1, B=0.4-0.5, C=0.2-0.3$, $\mathrm{D}=\mathbf{0} \cdot 10-0.5 \mathrm{~mm}$. diameter. as compared with 8.3 for the controls, a difference which is statistically significant $(p<0.05)$. Excluding spleen 18 the difference of the means is highly significant $(\mathrm{p}<0.01)$.

ARTERIOVENOUS COMMUNICATIONS In neither preparation did the material injected into the artery penetrate beyond the capillaries. The finest arterial vessels filled in the latex casts were approximately $12 \mathrm{~m} \mu$ in diameter and the smallest vessels seen in the $x$-ray films of the barium-gelatin preparations were of the same order of magnitude. Arteriovenous shunts were not observed. Direct connexion of artery to vein was occasionally seen through fine arterial branches of 15 to $20 \mathrm{~m} \mu$ diameter which ended in sinuses filled from the venous side. In a few spleens from the cirrhosis group some reflux of the injected material occurred from the veins during injection of the artery. In these the latex cast of the vein also showed some arterial filling. Careful dissection showed that the communication of artery and vein was established through irregularly round structures $10-15 \mathrm{~mm}$. in diameter situated in the periphery of the cast. Exactly similar structures were observed in the films of the barium-gelatin preparations. Histological examination of sections from the latter preparations showed that these structures were almost certainly artefacts and due to rupture of small vessels with spilling of the injected material into the splenic pulp.

\section{DISCUSSION}

The present findings show that although the total arterial and venous volume increased in cirrhosis in proportion to the size of the spleen there was a relatively greater increase in the arterial component. One factor contributing to this increase was the greater number of fine vessels of about $100 \mathrm{~m} \mu$ diameter. Histological examination of the bariumgelatin preparations showed that these vessels had similar histological appearances in cirrhosis and control groups, and it is impossible to say at present whether they represent the formation of new channels or the opening of pre-existing ones. In support of the latter are the studies in vivo of Knisely (1936), showing the presence of arteriolar sphincters in the normal spleen which control the amount of blood flowing to different zones. This finding of an increased arteriolar supply is consistent with histological observations of Moschcowitz (1948) who describes an almost angiomatous appearance of the spleen in long-standing portal hypertension.

The presence of arterial aneurysms in $50 \%$ of the cirrhosis cases will, even though they were small, be another factor contributing to the increased 
arterial volume. The reported incidence of aneurysms in routine necropsy series varies from $0.037 \%$ (Sherlock and Learmonth, 1942) to $10 \%$ in series where special attention was paid to the splenic artery (Ferrari, 1938; Owens and Coffey, 1953; Bedford and Lodge, 1960). Many of the aneurysms in the present cases, however, were small and situated deep in the hilum and indeed in a number were detected only after preparation of the latex casts. The association of aneurysms with portal hypertension is usually considered fortuitous, though the latter was present in $20 \%$ of the 159 cases collected from the literature by Owens and Coffey (1953). The present series is small but recent radiographic-injection studies by Kreel and Williams (1966) of a larger group also shows a significantly higher incidence in cirrhosis although small aneurysms such as demonstrated here may be found in control subjects. The small aneurysms are probably of little clinical significance although larger ones may be found in portal hypertension and their occasional rupture is responsible for sudden death.

It seems likely that the increased peripheral arteriolar supply, and possibly the aneurysms also, are an indication of an increased blood flow through the spleen. Williams, Parsonson, Somers, and Hamilton (1966) have recently shown in man, using a radioactive Xenon clearance technique, that the total splenic blood flow is increased in cirrhosis with splenomegaly and in the idiopathic portal hypertension and splenomegaly of the tropics. This increased flow, together with the opening up or formation of new vessels, is probably responsible for the periarterial haemorrhages which are such a constant feature of portal hypertension (McMichael, 1934). The present studies show, however, that the increased flow and arterial changes are not secondary to the development of arteriovenous shunts, as has been suggested by Franceschini (1948), Womack and Peters (1961), Cavalli, Pisi, Cacciari, and Orlandi (1961), and D'Addato (1963a and b.) This failure to demonstrate shunts cannot be attributed to the technique of injection since arterial vessels were filled to a size well below that expected for shunts, and the order of injection, with the artery done first, should give the best chance of filling arteriovenous anastomoses. Although there seems little doubt that arteriovenous communications, possibly under hormonal control and controlled by sphincters, are present in the normal mammalian spleen (Prinzmetal, Orniz, Simkin, and Bergmann, 1948; Parpart, Whipple, and Chang, 1955), there is therefore no evidence that these are widely dilated or that other direct arteriovenous communications occur in cirrhosis. It is possible also that a number of observations interpreted as evidence for ateriovenous shunts are due to changes in the preceding arteriolar vessels. Womack and Peters (1961) attributed an increase in portal blood flow and oxygen saturation after infusion of adrenalin to arteriovenous shunts but Parpart et al., (1955) showed by direct studies in mice in vivo that the effect of adrenalin was to straighten and shorten the path of the blood cells through the splenic sinuses, so decreasing the resistance. A similar effect may explain our observations and those of others (Womack and Peters, 1961) that the perfusion of the spleen in cirrhosis, as in the washing before injection, is easier than normal.

The cause of these arterial changes is uncertain but it seems likely that they are part of a generalized vascular response. Several studies have shown a high cardiac output in cirrhosis (Hecker and Sherlock, 1956; Murray, Dawson, and Sherlock, 1958) and the circulation through the skin and muscle is increased (Kontos, Shapiro, Mauck, and Patterson, 1964). Recent necropsy injection studies of the lung have shown very similar appearances to those present in the spleen with an increased number of small peripheral arterioles (Berthelot, Walker, Sherlock, and Reid, 1966). Whether the vascular response is related to cirrhosis or to the portal hypertension cannot be decided on necropsy studies since portal hypertension is usually present by the time of death. It is of interest that the one patient in the present series with a normal splenic vasculature had the shortest clinical history and the least evident signs of portal hypertension. The development of better methods of selective splenic arteriography (Kreel and Williams, 1964) will enable examination of the splenic circulation at various stages of cirrhosis during life and should help to answer this question.

\section{SUMMARY}

Techniques are described for the preparation of latex casts and of radio-opaque barium-gelatin preparations of the spleen. In both preparations the finest arterial vessels were filled and methods were developed for the quantitation of changes in the vascular pattern.

In cirrhosis the total arterial and venous volume increased in proportion to the size of the spleen. The arterial component showed a relatively greater rise and the number of small peripheral arterioles of approximately $100 \mathrm{~m} \mu$ diameter was increased. In $50 \%$ of the cirrhosis cases small arterial aneurysms were present, often deep in the hilum at the bifurcation of vessels. Arteriovenous shunts were not observed. 
The changes were thought to reflect an increased blood supply to the spleen, and the possible mechanisms are discussed in the light of changes in the arterial vasculature of other organs in cirrhosis.

We thank Professor K. R. Hill, Dr. Louis Kreel, and Professor Sheila Sherlock for their encouragement and advice. Dr. M. Petrelli helped with the histological sections and Mr. A. Parsonson gave valuable technical assistance.

\section{REFERENCES}

Bedford, P. D., and Lodge, B. (1960). Aneurysm of the splenic artery, Gut, 1, 312-320.

Berthelot, P., Walker, J. G., Sherlock, S., and Reid, L. (1966). Arterial changes in the lungs in cirrhosis of the liver-lung spider naevi. New Engl. J. Med., 274, 291.

Cavalli, G., Pisi, E., Cacciari, C., and Orlandi, F. (1961). Sulla presenza di anastomosi artero-venose e di dispositivi di blocco nei vasi intra-splenici. Arch. ital Mal. Appar. dig., 28, 113-123.

D'Addato, M. (1963a). Rilievi morfologici di angiotettonica splenica. Ibid., 30, 297-324.

- (1963b). I presupposti anatomici dell'ipertensione portale da iperafflusso splenico. Friuli med., 18, 5-14.

Ferrari, E. (1938). Contributo alla conoscenza degli aneurismi dell' arteria lienale. Cuore e Circol., 22, 585-604.

Franceschini, P. (1948). Splenomegalia, anastomosi artero-venose spleniche e malattia di Banti. Sperimentale, 99, 1-16.

Hecker, R., and Sherlock, S. (1956). Electrolyte and circulatory changes in terminal liver failure. Lancet, 2, 1121-1125.

Knisely, M. H. (1936). Spleen studies. Anat. Rec., 65, 23-50, 131-148.
Kontos, H. A., Shapiro, W., Mauck, H. P., and Patterson, J. L., Jr. (1964). General and regional circulatory alterations in cirrhosis of the liver. Amer. J. Med., 37, 526-535.

Kreel, L., and Williams, R. (1964). Arteriovenography of the portal system. Brit. med. J., 2, 1500-1503.

,$- \quad$ (1966). Splenic artery aneurysms in cirrhosis and normal subjects. In preparation.

McMichael, J. (1934). The pathology of hepatolienal fibrosis. J. Path. Bact., 39, 481-502.

Moschcowitz, E. (1948). The pathogenesis of splenomegaly in hypertension of the portal circulation: 'congestive splenomegaly'. Medicine (Baltimore), 27, 187-221.

Murray, J. F., Dawson, A. M., and Sherlock, S .(1958). Circulatory changes in chronic liver disease. Amer. J. Med., 24, 358-367.

Owens, J. C., and Coffey, R. J. (1953). Aneurysm of the splenic artery, including a report of 6 additional cases. Int. abstr. Surg. 97, 313-335.

Parpart, A. K., Whipple, A. O., and Chang, J. J. (1955). The microcirculation of the spleen of the mouse. Angiology, 6, 350-362.

Patrassi, G., Dalpalu, C., and Ruol, A. (1961). La pletora portale. Atti Congr. Soc. ital. med. interna, $62,506$.

Prinzmetal, M., Orniz, E. M., Jr., Simkin, B., and Bergmann, H. C. (1948). Arteriovenous anastomoses in liver, spleen and lungs. Amer. J. Physiol., 152, 48-52.

Ravenna, P. (1940). Banti's syndrome (fibrocongestive splenomegaly). Arch. intern. Med., 66, 879-892.

Shaldon, C. (1962). Dynamic aspects of portal hypertension. Ann. roy. Coll. Surg. Engl. 31, 308-329.

Sherlock, S. P. V., and Learmonth, J. R. (1942). Aneurysm of the splenic artery: with an account of an example complicating Gaucher's disease. Brit. J. Surg. 30, 151-160.

Tisdale, W. A., Klatskin, G., and Glenn, W. W. L. (1959). Portal hypertension and bleeding esophageal varices. New Engl. J. Med., 261, 209-218.

Williams, R., Parsonson, A., Somers, K., and Hamilton, P. J. S. (1966). Portal hypertension in idiopathic tropical splenomegaly. Lancet, 1, 329.

Womack, N. A., and Peters, R. M. (1961). The significance of splenomegaly in cirrhosis of the liver. Ann. Surg., 153, 1006-1019. 